\title{
Gender Equity in Clinical Trials in Canada: Aspiration or Achievement?
}

Roxanne Mykitiuk

Osgoode Hall Law School of York University, rmykitiuk@osgoode.yorku.ca

Patricia Peppin

Source Publication:

International Journal of Feminist Approaches to Bioethics 1:2 (2008) p. 100-124

Follow this and additional works at: https://digitalcommons.osgoode.yorku.ca/scholarly_works

Part of the Law Commons

\section{Recommended Citation}

Mykitiuk, Roxanne and Patricia Peppin. "Gender Equity in Clinical Trials in Canada: Aspiration or Achievement?" International Journal of Feminist Approaches to Bioethics , vol. 1, no. 2, 2008, pp. 100-124.

This Article is brought to you for free and open access by the Faculty Scholarship at Osgoode Digital Commons. It has been accepted for inclusion in Articles \& Book Chapters by an authorized administrator of Osgoode Digital Commons. 
Gender Equity in Clinical Trials in Canada: Aspiration or Achievement?

Patricia Peppin and Roxanne Mykitiuk

124.

(Fall 2008) 1:2 International Journal of Feminist Approaches to Bioethics 100-

Achieving gender equity in clinical trials requires that women be included in sufficient numbers to carry out analysis, that those sub-sample analyses be carried out, and that results be communicated in such a way as to expand medical knowledge, inform policy decisions and educate patients. In this article, we examine the extent to which Canada promotes gender equity through its laws and guidelines, viewed within the context of its drug safety system and its research ethics board structure. We analyze the structuring of information by the pharmaceutical industry and consider the impact of its promotional activities on the state of gender knowledge and health. In the final section we propose ways to improve the structuring of health information to promote gender equity.

\section{Introduction}

The case for inclusion of women in clinical trials has been well made since the $1980 \mathrm{~s} .{ }^{1}$ A number of considerations inform the need for sex and gender inclusion in the clinical trial process. Most importantly, unless drugs are tested on the entire population that will use them once the drug is on the market, we cannot be satisfied that health and safety have been adequately protected. A study of trials and meta-analyses of drug therapies for myocardial infarction published in five leading medical journals between 1992 and 1996 reveal that women were poorly represented (mean: 24\%), and that just under a third (32\%) of 42 reports reviewed provided results based on gender, while even fewer (12\%) discussed the differences between men and women. ${ }^{2}$ Cardiovascular disease is the leading cause of death of women in Canada and globally. 
Analysis of the data for individual sub-groups is essential to increasing our knowledge of a drug's effects. A study of clinical trials of Vioxx found that more women than men had been included (74 per cent were women) but that 80 per cent of the trials included no description of the drug's efficacy by sex. Only one trial reported adverse effects data by sex. ${ }^{3}$ This study also notes that in the Spanish trials of Vioxx, 78 per cent of the reported side effects of Vioxx were found in women. ${ }^{4}$ Further support for gender inclusion is found in the clear evidence of sexbased differences in pharmacokinetics and pharmacological effect (pharmacodynamics). ${ }^{5}$ These results have implications for dosage as well as the impact of the drug. For example, one postmarket study on paroxetine (Paxil/Seroxat) notes "the complete lack of coherent science-based advice on dosage...[which] is essential for the safe and effective use of most drugs, but is available for few."

The need for women's health research has been amply demonstrated through the Women's Health Initiative [WHI], the first longitudinal study of women's health. Starting in 1991, the WHI carried out a fifteen year program of research through clinical trials and an observational study on leading causes of death and disability among postmenopausal women: cardiovascular disease, cancer, and osteoporosis. ${ }^{7}$ Their clinical trial of hormone replacement therapy challenged conclusions about its benefits and risks, and led significant numbers of women to stop the therapy. ${ }^{8}$ Similarly, their study on long-term aspirin use revealed a differential impact on heart health as between men and women. ${ }^{9}$

By the 1990s women's activists had become concerned about the lack of representation of women in clinical trials and research. Women's health became the subject of international 
agreement at the United Nations Fourth World Conference on Women in Beijing in $1995 .{ }^{10}$ The Declaration produced at the Conference guarantees, among other things, equal access and treatment to men and women in education and health care. Canada adopted the Beijing Declaration and established The Federal Plan for Gender Equality in the same year. The Federal Plan called for research into participation in clinical trials and research. Health Canada also created a guideline on inclusion in clinical trials in 1997. ${ }^{11}$ Meanwhile, the federally funded research councils added a non-exclusion clause on the basis of sex to the Tri-Council Policy Statement, Ethical Conduct for Research Involving Humans $[T C P S] .{ }^{12}$ In the first part of this article, we will assess the merits of these and other developments in gender inclusion in drug safety research, and of the Research Ethics Board [REB] system through which they are implemented. In the second part we will analyze the role of the pharmaceutical industry in structuring health information and the way these activities undermine gender equity. This analysis is undertaken to assess whether gender equity in clinical trials has been achieved, or is still an aspiration.

\section{Canadian position on inclusion}

\section{Context}

Proper inclusion in clinical trials requires representation in sufficient numbers to permit analysis of data of sub-populations such as women and men, and elderly women and men, and members of ethnic minorities. To achieve the benefits of representation, it is necessary for researchers to perform the sub-sample analyses for each group in relation to the others. As well, to achieve gender equity, researchers need to consider the data in light of social factors that inform the concept of gender. These environmental and behavioural factors ${ }^{13}$ comprise the social 
determinants of health, and include income and social status, physical environments, culture, and sex. ${ }^{14}$ The unique health status of poor aboriginal women living in remote locations provides stark evidence of the relevance and significance of these determinants. ${ }^{15}$ Social determinants of health affect the ways women and men use the health care system, view their health, use prescription medications, and participate in clinical trials. ${ }^{16}$ To further respect women's interests, women need to be empowered to make their own decisions about participation in trials. Also, some trials should take place during pregnancy. Finally, women should not be pressured to participate by the drug industry or physicians, or be made to undergo trials as a means of obtaining otherwise inaccessible care.

Canada has taken a variety of steps to establish standards and organizations to implement its international commitments in the area of women's health. This institutional framework provides the context for a discussion of gender inclusion in research and clinical trials in particular and gender equity in health more broadly. Canada ratified the Convention on the Elimination of All Forms of Discrimination Against Women, article 12 of which requires the elimination of discrimination in the field of health and health care, with specific reference to pregnancy services. In 1993, the Canadian government established the Bureau of Women's Health within Health Canada (now referred to as the Bureau of Women's Health and Gender Analysis). The Bureau's mission is to promote equitable health outcomes for women and men, boys and girls. In 1999 the Bureau published the Women's Health Strategy, which focuses specifically on gender-based analysis, access and accountability. ${ }^{17}$ In 2000 Canada reiterated its 1995 commitment to the Beijing Declaration at the United Nations and published Health Canada's Gender-based Analysis Policy [GBA Policy], which provides an analytic framework within 
which to assess how government policies, programs, and legislation contribute to gender equality and to more equitable health outcomes. ${ }^{18}$ The Bureau of Women's Health and Gender Analysis describes GBA as using sex and gender to perceive social differences and contexts and to identify how these conditions affect health status and interactions with the health care system. ${ }^{19}$

As an example, they discuss the clinical trials policy, stating that applying GBA reveals gender bias and raises questions about the scientific validity of studies, resulting in the policy now requiring inclusion of both sexes unless the drug is intended for use in only one sex. The $G B A$ Policy recognizes that a gender perspective is essential to health policy and notes that full integration of gender analysis into planning and operations is required. ${ }^{20}$ The Women's Health Strategy provides the framework for integrating gender-based analysis into programs and policies. The Strategy outlines 64 key activities to meet its goals. One activity consists of monitoring the implementation of the inclusion guideline for women in clinical trials.

The Women's Health Bureau supports the Canadian Women's Health Network [CWHN] and five Centres of Excellence for Women's Health across the country. The CWHN has suggested that a review of the Women's Health Strategy would be timely, noting that in 2005 Health Canada told the Standing Committee on the Status of Women that it planned to review the Strategy. ${ }^{21}$ Olena Hankivsky, in her review for the CWHN of Canada's progress on women's health since the Beijing Declaration, concludes that progress has been made in the previous ten years, but that "much more work needs to be done to realize the federal government's commitments to Beijing and Beijing +5 , among other international obligations". ${ }^{22}$ Hankivsky points to six specific problems, among them the lack of a formal mechanism to ensure genderbased analysis in health research, the under-representation of women in health and science 
careers, gender bias in research methods and priorities, and the government's failure to regulate health matters in areas where it has the authority to do so, as it does with drug advertising. In addition, she notes that while the Women's Health Strategy had taken note of the need to be sensitive to diversity, it needs to take full account of the inequities experienced by women who are poor, disabled, aboriginal, or elderly. ${ }^{23}$

\section{Drug approval process}

The legislation governing drug approval is the Food and Drugs Act, a federal statute. ${ }^{24}$ The Act and the Food and Drug Regulations are silent on gender equity. ${ }^{25}$ In 1997 , Health Canada issued a guideline on inclusion to apply to all clinical trials, Inclusion of Women in Clinical Trials. ${ }^{26}$ The guideline asserts that, "[d]rugs should be studied prior to approval in subjects representing the full range of patients likely to receive the drug once it is marketed". The guideline also states that, "patients of both sexes should be included in the same trials in numbers adequate to allow detection of clinically significant sex-related differences in drug response" and further, that "[a]nalyses to detect the influence of sex should be carried out both for individual studies and in the overall integrated analysis of efficacy and safety."

The guideline's stated intent is to "encourage the inclusion of women, especially women of child-bearing potential, at the earliest stages of drug development" so that sex-related differences may be identified early and taken into account in Phase III safety and efficacy trials, and to ensure that data will be available to inform physicians and patients about sex-related drug qualities. This point is significant since it is at the early stage of research that the pharmacokinetics and pharmacological effects are identified. As the guideline notes, these differences might occur in dosage responses, maximum size of effect, or adverse effect risk. The 
guideline states that exclusion from early trials out of concern for fetal toxicity is not necessary because women can take adequate precautions against becoming pregnant and exposing a fetus to potential danger. ${ }^{27}$ According to the guideline, the decision of whether to enroll pregnant or lactating women in a particular trial needs to be individualized. Risk should be assessed by patients, their doctors, the manufacturer, and REBs, with oversight by the Therapeutic Products Directorate.

The guideline states the principle of inclusion in a forthright manner and develops the rationale for it. Since the guideline lacks the legal force of a regulation or statute, however, it is comparatively weak. In addition, its reasoning is undermined by its own wording which suggests a lack of willingness to enforce the guideline, since it is designed to "encourage" and "promote" inclusion. The Minister of Health may reject an application to market a drug on the basis that it fails to meet the requirements of the Food and Drug Regulations or that the application does not contain sufficient information for the Minister to assess the safety of the drug or of the clinical trial. ${ }^{28}$ This provision applies to those drugs not yet licensed for marketing and to those approved drugs being assessed for new uses, formulations and combinations. Since the inclusion guideline lacks the status of a regulation, it cannot be used directly to reject an application for failure to meet a regulation. Even though it is arguable that a lack of representation and analysis could provide the basis for Ministerial rejection on the basis of inadequacy of the information to assess the safety and efficacy of the drug or the clinical trial, only regulatory status for the inclusion principle would provide a clear and unequivocal basis for such a rejection. 
Reviewers of the safety and efficacy of new drug submissions must follow a standard operating procedure, which normally requires gender-based analysis as an evaluation method in a number of instances. ${ }^{29}$ Applying the inclusion guidelines at this stage, reviewers consider how the clinical trial population represents the population to whom the drug will be marketed. Where a drug is to be used by women it would be strongly recommended that it be tested on women. A drug tested only on men, for example, might only be allowed to be marketed to men. ${ }^{30}$ Gender might also be considered for safety reasons if a drug is under consideration for a new indication or if a drug under a notice of compliance with conditions is to go through post-market testing. The procedure provides at paragraph 4 , however, that "[d]eviations from this procedure may be acceptable, provided the deviations and their justification are documented in the assessment report." Further, the instructions are said to be "a guide for reviewers, but the inclusion or exclusion of information under a section is left to the scientific judgement and discretion of the reviewer." ${ }^{11}$ Timing such review during the safety and efficacy evaluation heightens its potential to enforce gender inclusion policy. Under the current legislation, the government has most power to effect changes during the approval process. The Minister is authorized under the Regulations to withhold approval for failure to meet standards but once the drug has been approved for marketing, the Food and Drugs Act provides scant authority to require changes. As Health Canada observes in its 2006 document, Blueprint for Renewal, "[i]ts [the Food and Drugs Act's] authorities for compliance and enforcement, based on criminal law, are outdated and resource intensive, which limits the range of actions that can be taken, including appropriate sanctions and incentives." ${ }^{32}$ Also, no systematic review mechanism to review the inclusion guideline had been put into place, in spite of the promise in the Women's Health Strategy of Health Canada to monitor the inclusion policy for clinical trials. ${ }^{33}$ The government itself has not 
reviewed the success or failure of its own policies on inclusion providing us little reason to be optimistic about their implementation. ${ }^{34}$

The International Conference on Harmonisation [ICH] has brought together six parties (the governments and pharmaceutical organizations from Japan, the European Union, and the United States) and three observers (Canada, the World Health Organization, and the European Free Trade Association), with a view to harmonizing drug approval processes among countries that choose to incorporate ICH practices into their governing legislation. As Health Canada states on its website, Canada has adopted and integrated the good clinical practice principles from the $\mathrm{ICH}$ Good Clinical Practice [ICH-GCP] guidelines into its 2001 regulations, though they do not have the force of law. ${ }^{35}$ Relying on the $I C H-G C P$ guideline is problematic to some extent because of the absence of a national regulatory scheme to fill in gaps and the absence of a process to ensure respect for the guideline. ${ }^{36}$ The 2001 Canadian regulations contain no explicit reference to gender equity. The regulatory impact statement analysis lists ICH guidelines that were to be adopted in Canada. ${ }^{37}$ These include Guideline E8 (General Consideration of Clinical Trials) stating the principle that the study population should represent the target population, as in the Canadian inclusion guideline - and requiring pharmacokinetic information for women in Phase I along with certain dose-response information to support drug registration. Further, guidelines E3 and M4E require sex-based identification of the patient population, analysis and critical assessment of the data by sex..$^{38}$ The impact of these policies is softened, however, by opting out statements such as "if the size of the study permits". ${ }^{39}$ As another example, the E6 (R1) Good Clinical Practice guideline currently states at 7.3.6, a provision relating to effects in humans, that, "[a] summary of information on the pharmacokinetics of the investigational product(s) 
should be presented, including the following, if available...[p]opulation subgroups (e.g. gender, age...)." Once again, the impact of this recommendation is limited by the words "should be presented" and "if available".

In March 2007, the Bureau of Women's Health and Gender Analysis and the Policy Coordination Division of Health Canada convened a day long conference entitled "Context Matters: A Health Canada Symposium on Gender, Diversity and Clinical Trials". The meeting brought together officials from both the Health Policy and Health Products and Food branches of Health Canada as well as a number of speakers to consider issues of equity in clinical trials with an emphasis on achieving greater diversity on the basis of gender, ethnicity (including aboriginal populations) and age (including children and the elderly). The conference organizers used the day long symposium as an opportunity to educate Health Canada officials about the importance of ensuring that gender and diversity considerations are included in the ongoing legislative, regulatory and policy review. Numerous questions on gender and health were addressed. One speaker, Yvonne Lefebrve, after reviewing the history of the representation of women in clinical trials, concluded by suggesting that the outstanding issues are: monitoring and evaluating the appropriate representation of women in clinical trials and determining whether there is compliance with current standards/regulations; the sex-based disaggregation of data; the need for policies regarding equity and conducting international clinical trials; the inclusion of pregnant women and the representation of diverse groups of women.

\section{Tri-Council Policy Statement, Ethical Conduct for Research Involving Humans}


The TCPS was adopted following extensive negotiations among the three federally funded granting councils, in order to create a common standard for funded research, regardless of discipline. The composition of REBs and their mandate to review and approve biomedical research involving humans and to conduct periodic reviews is set out in the Food and Drug Regulations. ${ }^{40}$ The structure and mandate of REBs are also specified in the TCPS, though in somewhat different terms. Clinical trials must be approved by REBs as part of the Food and Drugs Act drug approval process. ${ }^{41}$ Although the Therapeutic Products Directorate has indicated that all clinical trials are to adhere to the TCPS, a question may be raised about whether this is enforceable. ${ }^{42}$ As Mark Hadskis has commented, "[d]etermining when a particular activity is captured by the TCPS is not always a straightforward matter." ${ }^{\text {"3 }}$ The TCPS applies to any research, defined as systematic inquiry to prove facts, principles or generalizable knowledge that is directly or indirectly funded by the granting councils. Also, following the requirements of the TCPS may be a term of private agreements among institutions or be a requirement of regulatory bodies. Peer-reviewed journals and courts may also promote compliance with the policy statement. ${ }^{44}$ The TCPS does not apply in a general manner outside of these contexts. ${ }^{45}$ The TCPS is enforced mainly through the denial of funding to proposed research. Rarely, an institution conducting approved and funded research which turns out to not to conform to TCPS requirements may be made to return funding.

The TCPS contains one statement dealing primarily with gender equity: that "[w] omen shall not automatically be excluded from research solely on the basis of sex or reproductive capacity". 46 In addition, where research is not specific to a group, Article 5.1(a) prohibits researchers from excluding subjects at the recruitment or research stage based on such attributes as culture, race, 
disability, sex, and so on. These provisions can only be described as weak and ineffectual. ${ }^{47}$ By prohibiting only the most egregious exclusions - automatic exclusion solely on sex or reproductive grounds - they permit even non-arbitrary sex-based exclusion. ${ }^{48}$ Similarly, exclusion is permitted when a "valid reason" is offered. The provisions contain no requirement that samples contain sufficient numbers for sub-sample analysis to be carried out or that such sub-sample analysis be done. An earlier version of these provisions contained stronger language which was "gutted" by the councils. ${ }^{49}$ Françoise Baylis, Jocelyn Downie and Susan Sherwin have described their reaction to the process: "To our surprise and dismay, the first official draft Code of Conduct for Research Involving Human Subjects reduced all of the above proposals to a single prescriptive clause that clearly sought to mask the gendered nature of the problem of exclusion and underrepresentation...."

REB review plays a central role in protecting patient safety in the Canadian system. The Law Commission of Canada's review of REB governance commented on the excessive and virtually total reliance on REBs to provide assurance of ethical compliance. ${ }^{51}$ No formal qualitative review or accreditation process for REBs exists at this time. Health Canada noted this deficiency at the time the 2001 Food and Drug Regulations were put into place, and yet justified not placing more responsibility on REBs than they had already. ${ }^{52}$ Currently, the National Council on the Ethics of Human Research provides organizational oversight and has supported the implementation of a voluntary accreditation and certification system. ${ }^{53}$ Trudo Lemmens has argued in favour of federal oversight of REBs on the ground that REBs have a public mandate to protect research subjects and the public. ${ }^{54}$ The variations in the legal force of the multiple laws, international documents, and guidelines, along with the differences in law applying within 
provincial and territorial jurisdictions, add to the complexity of the task of evaluating proposed research. The increasing number of multi-site clinical trials and the specialized nature of research create other demands on local REBs. Kathleen Cranley Glass has described the structure in these terms: "[t]he current system of research governance is fragmented and decentralized, without a consistent, accountable, and transparent system of ethics review. We have yet to establish a comprehensive, uniform set of standards or structure for review that would apply to all research involving humans. There are no viable systems of education, accreditation, or monitoring." ${ }^{55}$

One significant drawback of the REB system in Canada is the lack of monitoring of clinical trials and research. ${ }^{56}$ Although monitoring clinical trials is part of the REB mandate, ${ }^{57}$ many institutions provide insufficient support to carry out oversight after the protocol has been approved. ${ }^{58}$ The Therapeutic Products Directorate's 2002 Inspection Strategy for Clinical Trials estimated that the Therapeutic Products Directorate would inspect only two per cent of clinical trials involving human subjects, ${ }^{59}$ a rate described as the international norm. ${ }^{60}$

\section{Drug safety}

The problems in the area of REB review are compounded by the known deficiencies in the system of drug approval and oversight. Health Canada has reviewed the drug approval process and incorporated many of its findings into two documents, Blueprint for Renewal [Blueprint $]^{61}$ and the revised version following consultation, Blueprint for Renewal II [Blueprint II]. ${ }^{62}$ Most recently, the Minister of Health has introduced a Bill that, if passed into law, will notably change Canada’s drug approval process. ${ }^{63}$ 
A brief consideration of issues facing the drug approval and oversight system in the United States is helpful. In 2006, the United States Government Accountability Office [GAO], the investigative arm of Congress, identified serious problems in the FDA's oversight of safety once the product reaches the market. ${ }^{64}$ The 2006 GAO Report considers oversight to have been compromised by lack of tracking of information about safety issues, lack of criteria to tell both when safety decisions should be taken and what decisions to take, weak data, and poor decisionmaking processes. In other words, the most powerful drug regulation agency in the world does not know when or how to make decisions about the safety of drugs. Furthermore, the GAO report notes that the FDA lacks legal authority in most instances to order a company to carry out further tests of safety once its product is on the market.

The Institute of Medicine [IOM] released its much-anticipated report on drug safety soon after, in September 2006. ${ }^{65}$ This report identifies significant impairments in the drug safety system resulting from severe funding constraints which weakened scientific analysis of drug safety, a less than optimal organization culture, and inadequate regulatory authority, most notably with respect to enforcement. The IOM report includes a lengthy list of recommendations directed to a fundamental restructuring of the drug approval process. Among the proposals that would have a significant impact if adopted in Canada are: the limited licensing of new drugs, similar to the progressive licensing framework supported in Blueprint and Blueprint II; labelling requirements to warn consumers that the product is a new drug; an advertising ban for new drugs; mandatory registration of clinical trial results to improve access to drug safety information; and the authority 
to withdraw the product from the market, impose fines and issue injunctions for failure to meet obligations to carry out safety studies.

While we need to exercise caution in generalizing about drug approval systems, it is clear that any drug safety system that is broken in such fundamental ways lacks the ability to effectively promote public safety and health. The deficiencies in drug safety inevitably have an impact on the ways data on women's health are gathered, assessed and used. Reforms directed to inclusion and gender equity will be effective only with a broad overhaul of the drug safety system. In Canada, the weak "guarantees" of a guideline and a virtually useless research standard are unlikely to have much impact in a system suffering from its own identified weaknesses.

Canada's recently introduced Bill to amend the Food and Drugs Act, if enacted, will constitute a significant restructuring of the drug approval process. The Bill addresses many of the concerns noted in Blueprint and Blueprint II by developing a progressive licensing framework for drug approval, setting a new standard for risk assessment, and providing means to secure more information about product risks. Under the new framework, the Minister is given the power to grant market approval with conditions, to amend those conditions following notice and a hearing, to suspend or revoke a clinical trial authorization in particular circumstances, and to grant licenses for limited uses of drugs. The new standard to be met for drug approval is Ministerial satisfaction that the benefits provided by the drug outweigh the risks. If adopted, the risk-benefit standard will mark a change from a more precautionary principle that requires standards to be met after technical review. The Bill significantly expands the Minister's power over regulation and reporting in the post-market period. The Minister will have the power to compel the holder 
of a market authorization or establishment licence to compile information, conduct tests or studies or monitor experience to obtain additional information relating to the product's effects on health or safety or to report this information to the Minister. As well, subject to the Regulations, the Minister may compel production of information under their control that is considered necessary to administer the Bill. Significantly, the Bill enables the Minister to require any labelling necessary to prevent injury to health, a reassessment of a therapeutic product within a set time, and public disclosure of information about risks and benefits.

Bill C-51 does not directly take up issues of gender equity or sub-population testing, although those issues may be addressed in the regulations and through the related initiatives being taken by the government. Blueprint highlights the need to emphasize specific populations in research and policy, noting possible differences in drug responses to drugs and the need to address specific needs, ${ }^{66}$ Even so, the Bill has implications for achieving gender equity in clinical trials and drug safety more generally. For one thing, though progressive licensing can be used to ensure drug safety, it can also be used to approve drugs for marketing more quickly. This latter possibility may create tension with the goal of promoting safety. Blueprint II indicated that the government would consider early access mechanisms in its progressive licensing framework to address the particular therapeutic or health needs of specific populations. ${ }^{67}$ Earlier availability can mean that a drug is available earlier to a broader and more representative population than would have been possible at that stage under the current system, but without necessarily having completed clinical trials on the full range of populations who will use it. Only if post-market testing is actually achieved will this change be successful for the entire population who will be exposed to the drug. With respect to risk management, Women and Health Protection, in their 
comment on Blueprint, state that an emphasis on "managing risk" would replace the precautionary principle of health protection. ${ }^{68}$ While under the new Bill it is the applicant that must establish that this risk-benefit standard is met, the terms will be subject to wide interpretation. Therefore, without some guidance, Ministerial decision-making on this issue raises the possibility of the politicization of the drug approval process. Because the drug regulation system operates within government rather than through an arm's length agency, the prospect of politicization is real. Finally, with respect to access to therapeutic information or disclosure, the language of the Bill is permissive, stating that the Minister "may" disclose to the public information about the risks or benefits associated with a therapeutic product. These shortcomings may serve to exacerbate whatever inequalities women experience in the clinical trial/drug safety context.

In contrast to the above concerns, increased oversight in the post-market period greatly favours drug safety and efficacy for the broader range of groups that will use the drugs once marketing commences. Significant improvements in the availability and accessibility of information may be achieved through the new powers to be attributed to the Minister. Specifically, the Minister will be able to acquire information through the creation of a publicly accessible register of information, through the potential revealing of confidential business information in certain circumstances, and through mandatory reporting of adverse drug reactions [ADRs] by prescribed institutions. The promotional aspects of information distribution are addressed in several changes addressing criteria for fraud or deception and in a change prohibiting advertisement unless authorized by the regulations, although the Bill does not address directly the issue of direct-to-consumer advertising. Strengthened powers of administration and enforcement, 
expanded powers for inspectors, enhanced remedies for offences, including injunctions, more realistic fines and imprisonment, application of offences to directors and other persons who are parties within corporations, and the requirement that sentencing take into account the harm or risk and vulnerability of consumers are all likely to enhance health information and safety. The impact of the legislation will depend though on the regulations and on the will of the Minister.

\section{Common law}

While we are unable to explore this issue in detail, it is worth raising the question of whether a tort lawsuit could be successful based on failure to test drugs on women. ${ }^{69}$ It can be argued that an action targeting testing inadequacies would provide an important impetus to manufacturers to include women in their studies, countering the fears of litigation that led drug manufacturers to exclude women. Litigation on this basis might help persuade the industry that it is in their interest to include representative samples and to analyze these data. At the same time, one must ask whether testing drugs on women could itself lead to legal liability. Ellen Wright Clayton has suggested not, writing, "the risk of incurring liability during the early stages of drug investigation is actually quite small whereas the potential for substantial liability is much greater once a fetotoxic drug enters widespread use." $" 70$

\section{Summary}

An overview of Canada's position on gender inclusion in clinical trials reveals numerous achievements, yet also shortcomings which leave ample room for further development. Women's activism and international developments in the United Nations and the United States have caused the Canadian government to address the issue of how to include women in clinical 
trials so as to come closer to achieving gender equity in health. The government and affiliated groups have produced policy documents and guidelines. Though perhaps commendable, these guidelines lack the force of law and do not even attempt to require conduct or check to see whether goals have been met. These limitations are exacerbated by the drug safety and research ethics board context within which the guidelines operate. The proposed amendments to the federal food and drug legislation holds out the promise of increased amounts of health information and greater control by government over the process; however, it is too soon to say whether the move to progressive licensing and a risk-benefit standard will enhance or diminish gender equity. The mechanisms chosen to achieve gender equity remain outside the legislative framework. Finally, while the threat of tort litigation might induce drug developers to increase testing of their products on women, this potential cause of action remains untested. The next section of this paper looks more closely at the role of the pharmaceutical industry in gender equity in health.

\section{The role of the pharmaceutical industry in gender equity in health}

One aspect of gender equity in health is the creation of health information that can serve to improve women's health. For this reason, the way information is constructed and transmitted needs to be assessed. Information collected about women's reactions to drugs is gathered and filtered through the pharmaceutical company's promotional lens. The drug industry creates knowledge about their products in a literal and scientific sense through the process of drug research, through the presentation of results to the regulator, through publication of research results in journals, and through promotional activities. ${ }^{71}$ We have become acutely aware of the dramatic breakdown in the transmission of reliable information through these channels. For 
example, the cox-2 inhibitor Vioxx was portrayed as a safe and effective means of controlling pain for arthritis patients and its risks were obscured, as was demonstrated in the Report prepared by Representative Henry Waxman for the U.S. House Committee on Government Reform, which provided a rare glimpse of the activities of drug sales representatives (detailers) in their interactions with doctors. ${ }^{72}$ Similarly, the antidepressant paroxetine, known as Paxil in North America and Seroxat in Great Britain, was being used extensively among adolescents until the BBC program Panorama aired the first in its series of post-market reports on the drug which stimulated an outpouring of evidence of the significant risk of suicide and suicidal ideation. ${ }^{73}$

Sources that appear to be neutral and unbiased, such as government advisory panels and peerreviewed journals, have had underlying conflicts of interest unmasked. ${ }^{74}$ As John Abramson notes in Overdosed America, drug companies may withdraw advertisements from a journal if their needs are unmet, while, "[t]he journals benefit from the publicity gained from publishing large drug company-sponsored studies. This increases the value of their advertising and enables them to sell back to the drug companies reprints of articles, which the drug companies then distribute as marketing tools to doctors." 75 Corruption of the information-distribution process has occurred through ghost-writing of articles by industry, industry-funded patient advocacy groups, sponsored conferences and selective publication of results. ${ }^{76}$ As the integrity of the process is jeopardized and health information is skewed, the accuracy of the information applying to women comes into question and women's health is affected.

Promotion by the pharmaceutical industry creates diseases that can be cured by pills - "selling sickness" or "disease-mongering", in other words. ${ }^{77}$ Pharmaceutical products create the image of 
an answer to a "disease" that is aptly described as industry-created, examples being social anxiety disorder or baldness. The dual myths of the need for intervention and of the need for a particular drug's intervention are created through these images. ${ }^{78}$ Intervention through dealing with underlying problems linked to the social determinants of health has no appeal to the drug industry. Poverty, chronic joblessness, social environments, gender and culture, and a range of other social determinants influence health and access to the health system. Buying into the pharmaceutical model - interventionist, individualistic, technological - leads individuals and governments away from the collective, community-focused and preventive public health solutions. The social determinants of health approach is linked to gender-based analysis, which helps us to understand how the experiences of women and men are different and similar and how health status, health needs and health care utilization differ. ${ }^{79}$ Pharmaceutical intervention ignores these links.

These flaws in the construction and transmission of health information have an impact on gender equity. Distortions in data diminish the impact of gender inclusion policies. Gender representation in research is essential to creating knowledge about the impact of drugs on the experiences of women and men. Unless the research is done, and the results accurately conveyed to all who need them, the impact on women's health will likely be unjust.

ADR data need be comprehensively examined to determine whether and how gender is a factor. Women have been found to experience more ADRs than men. This result is sometimes attributed to women's greater exposure to health professionals and higher level of drug-taking. Bates and Leape have reported on studies that indicate that women have a 
rate of ADRs $50 \%$ higher than men and consider whether these rates may be affected not only by the greater frequency of medical attention and drugs but also by the periods of women's lives when pharmacokinetics are affected: menarche, pregnancy and delivery, lactation, and menopause. ${ }^{80}$ Could it also result from lack of knowledge about the impact of drugs on women, or on particular groups of women? Beard and Lee ${ }^{81}$ have noted that, “[i]n general, women appear to be at greater risk of ADRs than men. Female patients appear to have a 1.5-1.7-fold greater risk of developing an ADR. ${ }^{82}$ The reasons for this are not entirely clear, but include gender-related differences in pharmacokinetic, immunological and hormonal factors, as well as differences in the pattern of medicine use." Elderly women, who make up the majority of elderly people, take multiple prescriptions whose interaction effects remain largely unstudied. Boxer and Shore have described the impact in these terms: "[a]dverse drug reactions occur about twice as often in older than younger patients... Risk of an adverse drug reaction increases with greater severity of illness, multiple comorbidities, smaller body size, changes in hepatic and renal metabolism and excretion, and prior drug reactions." ${ }^{83}$ Studies demonstrate the lack of inclusion and representation of those who will use drugs, with specific reference to elderly patients. One study notes, "NSAIDs are commonly used in elderly people because of the high prevalence of musculoskeletal disorders, especially in women. However, in the major drug trials evaluating NSAIDs, only $2.1 \%$ of patients were 65 years of age or over and less than $0.1 \%$ were over 75. In practice, elderly people are among the largest users of drugs and have the highest incidence of serious drug-related side effects." 84 
In light of these and similar flaws in gathering health information, we have several recommendations for change in the pharmaceutical industry and in regulatory oversight. First, knowledge about drug reactions needs to be collected in a broad and systematic manner. The Canadian system, like the American, collects drug information through mandatory reporting by drug companies to government and through voluntary reporting by doctors and hospitals. It is possible for Canadian consumers to report directly online, but the weight given to self-reporting is not indicated. When the BBC program Panorama ran the first of its series of programs on the antidepressant Seroxat, they received 1374 emails, as well as letters and 862 website communications from viewers who described their own experiences with the drug. An analysis of these results concluded that the picture created by reading the reports provided more complete data, including reports of suicides that had not been reported to the British authorities, and contained the context of the events so that the data could be evaluated and the impact on health more realistically assessed. ${ }^{85}$ Another study looks at the printouts of reports from the Yellow Cards submitted by physicians and other health professionals over 12 years (1990-2002) on adverse effects of paroxetine. Comparing the professional reports with the reports from patients in the previous study, the authors observe that patient reports "communicate essential information which professional reporters can never be expected to provide. In this case, patients provided reports that were much richer in their descriptions of behavioural phenomena and feelings than the YC [Yellow Card] reports and often much better at explaining the nature, significance and consequences of adverse drug effects. Patient reports convert the more technical terms that professionals use into understanding." ${ }^{.86}$ 
The voluntary reporting system results in significant underreporting of adverse events, at a level estimated at 10 per cent of what had been experienced and even the study of the mandatory Yellow Card system found a significant degree of underreporting. ${ }^{87}$ Patient safety is jeopardized when early identification of risks is undermined, particularly in the immediate post-market period when the number of individuals exposed to drugs is significantly increased and the drug is provided to people on whom the drug was not tested. As women experience more ADRs than men, this risk falls disproportionately on women. While Canada's proposed legislative changes would require ADR reporting by prescribed classes of institutions prescribed by the regulations, this is only a first step.

Adverse effects data-gathering must become much more efficient, accurate and contextual in order to protect public health. Health Canada has suggested several approaches to remedy the current deficiencies, including requiring industry to make a submission prior to approval of their plans for pharmacovigilance in the post-market period; establishing the authority under the Regulations to require post-market studies; collaborating to develop head-to-head comparison studies and large observational studies; addressing under-reporting; developing active surveillance systems; and increasing government's capacity to assess safety signals. ${ }^{88}$ Another way to achieve this goal is by paying attention to and recording patient descriptions of adverse reactions. The deficiencies of the adverse effect reporting system in Canada have been on Health Canada's radar for decades and it is time for these useful suggestions to be fully assessed and implemented. 
Next, reliable sources of information that are fully independent of the industry are needed to maintain the integrity of the public process and restore confidence in the system. An independent evaluator of information is also required to inquire into such issues as gender inclusion and drug advertising. Having industry pay to have clinical trial data evaluated in the process of drug approval in the United States has led to speedy trials, but these have been linked to a higher level of drug recalls. Eight out of ten drugs withdrawn by the FDA between 1997 and 2000 - a very high rate of withdrawal in itself - had greater health risks for women. ${ }^{89}$

Also, doctors and patients need to be made fully aware of the populations on whom the drug has been tested and the results. ${ }^{90}$ Access needs to be given to data submitted during the approval process, and unless it is, doctors and patients will lack information that is vital to decisionmaking. ${ }^{91}$ To give meaningful access, the government would need to require release of data from companies concerned about revealing trade secrets, as in the proposed legislation. ${ }^{92}$

Finally, a strong need exists to monitor the inclusion of representative populations through an independent entity. Such an entity should also review drug advertising to prevent the use of stereotypes and to prevent promotion from undermining disclosure. Advertisements directed to prescribing professionals need to be subject to enhanced scrutiny on this basis, supported by regulations. Direct-to-consumer advertising, ostensibly prohibited in Canada, needs to be prohibited in fact. An independent agency could assist in monitoring the distribution of broadcast, print and on-line ads. Several authors have suggested that an independent entity of this sort should review the clinical trials process as a whole. ${ }^{93}$ 


\section{Conclusion}

The Canadian government has indicated its strong support for gender equity through its policy statements, institutional structures and guidelines. At the same time, it has not fully translated these aspirations into concrete achievements, either by enacting legislation or through administrative oversight. In considering the ways the pharmaceutical industry presents drug information and in the over-emphasis on research ethics board review as the mechanism for monitoring the ethical aspects of drug trials, it is apparent that there is room for improvement in achieving the aspirations of the inclusion policy. We have pointed to the need for specific reforms in the areas of drug approval and the creation of knowledge about drugs as a means to realize these goals. Gender inclusion has significant health rewards for women. Achieving inclusion requires a commitment to using effective legislative and administrative mechanisms, including those that will enhance safety and the provision of health information, to achieve the benefits of the inclusion commitment.

\footnotetext{
* We are grateful to Mark Pioro, Joel Caldwell, Candice Skelton, and Tyler McAuley who provided valuable research assistance on this project. We would also like to thank our sources at Health Canada for clarifying our discussion of the application of guidelines and policies and the anonymous peer reviewers of this article for their insightful comments.

${ }^{1}$ Kinney, et al. 1981; Rosser 1989; United States General Accounting Office 1990; Merton. 1993; Dresser 1992; Institute of Medicine 1994; Merkatz 1998.

${ }^{2}$ Rochon, et al. 1998. The journals were the British Medical Journal, the Journal of the American Medical Association, the Annals of Internal Medicine, Lancet and the New England Journal of Medicine.

${ }^{3}$ Ruiz Cantero and Pardo 2006.
} 
${ }^{4}$ Cascales, Ruiz Cantero, and Pardo 2001; cited in Ruiz Cantero and Pardo 2006.

${ }^{5}$ United States FDA 1993; United States General Accounting Office 2001b; Peppin 2003.

${ }^{6}$ Medawar and Herxheimer 2003/04, 17.

${ }^{7}$ Women's Health Initiative 2008.

${ }^{8}$ Rossouw, et al. 2002.

${ }^{9}$ Lori Mosca, et al. 2007, 1231.

${ }^{10}$ United Nations 1995.

${ }^{11}$ Health Canada, Therapeutic Products Directorate Guidelines 1997; Tri-Council Policy Statement, Ethical Conduct for Research Involving Humans 1998. [TCPS].

12 Health Canada, Therapeutic Products Directorate Guidelines 1997; TCPS.

${ }^{13}$ Lalonde 1981.

${ }^{14}$ Health Canada 1999. The twelve health determinants identified by Health Canada are: income and social status, employment and working conditions, education and literacy, social environments, physical environments, healthy child development, personal health practices and coping skills, health services, social support networks, biology and genetic endowment, gender and culture.

${ }^{15}$ MacIntosh 2005.

${ }^{16}$ Lippman 2006.

${ }^{17}$ Health Canada 1999. See also The Canadian Women's Health Network 2007.

${ }^{18}$ Health Canada 2000.

${ }^{19}$ Health Canada 2000.

${ }^{20} 6$.

${ }^{21}$ Canadian Women's Health Network 2007.

${ }^{22}$ Hankivsky 2006.

${ }^{23} 3$.

${ }^{24}$ Food and Drugs Act, R.S.C. 1985, C. F-27.

${ }^{25}$ Food and Drug Regulations, C.R.C., c. 870. Part C of the Food and Drug Regulations deals with drugs and Division 5 of Part C specifically with "Drugs for Clinical Trials Involving Human Subjects". 
${ }^{26}$ Health Canada, Therapeutic Products Directorate Guidelines 1997.

${ }^{27}$ The guideline adds that women should be provided with adequate counselling.

${ }^{28}$ Food and Drug Regulations, C.R.C., c. 870, s. C.05.006(b). The Minister is authorized under section. C.05.016 and C.05.05.17 to refuse an application, and to suspend or to cancel sale, where the sponsor has failed to meet the regulatory requirements.

${ }^{29}$ Health Canada. 2006b.

${ }^{30}$ Officials at the Therapeutic Products Directorate of Health Canada, telephone conversations, 15 May 2008.

${ }^{31}$ Health Canada. 2006b.

32 Health Canada. 2006a; Health Canada 2007.

${ }^{33}$ Caron 2003, Hankivsky 2006; Lemmens 2005; Tudiver 2006.

${ }^{34}$ Hankivsky has provided a startling example of the government's own failure to give effect to gender-based analysis, in the report by the Romanow Commission on the Future of Health Care in Canada in 2002 and the First Ministers' Health Accord on Health Care Renewal in 2003.

${ }^{35}$ Food and Drug Regulations, C.R.C., c. 870, s. C.05.010; Health Canada 2004. See also discussion in Hadskis 2007, 264-66.

${ }^{36}$ Glass and Lemmens 2002, 477.

${ }^{37}$ S.O.R./2001-203.

${ }^{38}$ International Conference on Harmonization.

${ }^{39}$ Ruiz Cantero and Pardo 2006, 911-12.

${ }^{40}$ Food and Drug Regulations, C.R.C. c. 870, s. C.05.001.

${ }^{41}$ Food and Drug Regulations, C.R.C. c. 870, s. C.05.006.(1)(c).

${ }^{42}$ Lemmens and Miller 2003.

${ }^{43}$ Hadskis 2007, 262.

${ }^{44}$ Hadskis 2007, 263-64.

${ }^{45}$ Hadskis 2007, 262-264; Glass 2006, 40; Glass and Lemmens 2002.

${ }^{46}$ TCPS, Article 5.2.

${ }^{47}$ McDonald 2001. 
${ }^{48}$ Both Lippman 2006, 10 and Hankivsky 2006, 19-20 have criticized the TCPS inclusion clause.

${ }^{49}$ McDonald 2001, 9 citing Baylis, Downie, and Sherwin 1999.

${ }^{50}$ Baylis, Downie, and Sherwin 1999.

${ }^{51}$ McDonald et al. 2000.

${ }^{52}$ S.O.R./2001-203.

${ }^{53}$ Lemmens 2005, 42 and n7; see also McDonald, et al. 2000, who makes a similar argument.

${ }^{54}$ Lemmens 2005, 42-3.

${ }^{55}$ Glass 2006, 44.

${ }^{56}$ Hadskis 2007, 283-84.

${ }^{57}$ An REB is defined as "...a body that is not affiliated with the sponsor, and (a) the principal mandate of which is to approve the initiation of, and conduct periodic reviews of, biomedical research involving human subjects in order to ensure the protection of their rights, safety and well-being...." Food and Drug Regulations, C.R.C., c. 870, s. C.05.001.

${ }^{58}$ McDonald 2001, 12.

${ }^{59}$ Health Canada, Health Products and Food Branch Inspectorate 2002, s. 3.3.

${ }^{60}$ Health Canada, Health Products and Food Branch Inspectorate 2002.

${ }^{61}$ Health Canada 2006a.

${ }^{62}$ Health Canada 2007.

${ }^{63}$ An Act to amend the Food and Drugs Act and to make consequential amendments to other Acts. 2008.

${ }^{64}$ United States Government Accountability Office 2006, 27-29.

${ }^{65}$ Institute of Medicine 2006.

${ }^{66}$ Health Canada 2006a, 22-23.

${ }^{67}$ Health Canada 2007, 26-27.

${ }^{68}$ Women and Health Protection 2006.

${ }^{69}$ Flannery and Greenberg 1994.

${ }^{70}$ Clayton 1994, 103.

${ }^{71}$ Peppin and Carty 2001.

${ }^{72}$ Waxman 2005. 
${ }^{73}$ BBC Panorama 2002.

${ }^{74}$ Abramson 2004.

${ }^{75}$ Abramson 2004, 112-13.

${ }^{76}$ Healy 2003.

${ }^{77}$ Heath and Henry 2002; Moynihan and Cassels 2005.

${ }^{78}$ Peppin and Carty 2001.

${ }^{79}$ See Lippman 2006; Hankivsky 2006.

${ }^{80}$ Bates and Leape 2000, 1225; citing Wilson 1984.

${ }^{81}$ Beard and Lee 2006, 10.

${ }^{82}$ Beard and Lee 2006, n. 50; citing Rademaker 2001.

${ }^{83}$ Boxer and Shorr 2004, 421.

${ }^{84}$ Rochon, Berger, and Gordon 1998, 1373; citing data from Rochon, et al. 1993.

${ }^{85}$ Medawar, et al. 2002.

${ }^{86}$ Medawar and Herxheimer 2003/4, 15.

${ }^{87}$ Medawar and Herxheimer 2003/04, note 11.

${ }^{88}$ Health Canada 2006a, 21-2.

${ }^{89}$ United States General Accounting Office 2001a.

${ }^{90}$ Health Canada has taken steps to make some data available to the public on its website, MedEffect, which contains advisories, warning and recalls. The Notice of Compliance website is a searchable site for all drugs with a Notice of Compliance since 1994. Health Canada 2006a, 13.

${ }^{91}$ Women and Health Protection 2006.

92 Medawar and Herxheimer 2003/2004, 18.

${ }^{93}$ Avorn 2005.

\section{References:}

Abramson, John. 2004. Overdosed America: The broken promises of American medicine. New York: HarperCollins. 
An Act to amend the Food and Drugs Act and to make consequential amendments to other Acts. 2008. Bill C-51, 2d Sess. 39 ${ }^{\text {th }}$ Parl.

Avorn, Jerry. 2005. Powerful medicines: The benefits, risks, and costs of prescription drugs. New York: Vintage Books.

BBC Panorama. 2002. The secrets of Seroxat. http://news.bbc.co.uk/1/hi/programmes/panorama/2310197.stm. Accessed 7 March 2007.

Bates, David W. and Lucian Leape. 2000. Adverse drug reactions. In Melmon and Morelli's clinical pharmacology: Basic principles in therapeutics, $4^{\text {th }}$ ed, ed. S. George Carruthers, 12231256. McGraw-Hill.

Baylis, Françoise, Jocelyn Downie, and Susan Sherwin. 1999. Women \& health research: From theory to practice to policy. 253-68. In Embodying bioethics: Recent feminist advances, ed. A. Donchine \& L. Purdy. Lanham: Rowan \& Littlefield.

Beard, Keith and Anne Lee. 2006. Introduction. In Adverse drug reactions, ed. Annie Lee, 1-22. London: Pharmaceutical Press.

Boxer, Rebecca and Ronald Shorr. 2004. Principles of drug therapy: Changes with aging, polypharmacy, \& drug interaction. In Current geriatric diagnosis \& treatment, ed. C. Seth Landefeld, Robert M. Palmer, Mary Anne Johnson, C. Bree Johnston, and William L. Lyons, 421-35. New York: Lange Medical Books/McGraw-Hill.

Canadian Women's Health Network. 2007. What is Health Canada's Women's Health Strategy? http://www.cwhn.ca/resources/cwhn/strategy.html. Accessed 29 January 2008.

Caron, Joseph. 2003. Report on Governmental Health Research Policies Promoting Gender or Sex Differences Sensitivity. www.cihr-irsc.gc.ca/e/25499.html. Accessed 30 January 2008.

Cascales, S., Maria Teresa Ruiz Cantero, and M.A. Pardo. 2001. Clinical trials with rofecoxib: Analysis of the information from the gender perspective. Med clin (Barc) 120: 207-12.

Clayton, Ellen Wright. 1994. Liability exposure when offspring are injured because of their parents' participation in clinical trials. In Workshop and Commissioned Papers, 103-112.

Dresser, Rebecca. 1992. Wanted: Single, white male for medical research. Hasting Centre report 22(1): 24-29.

Edgar, Harold and David J. Rothman. 1995. The institutional review board and beyond: Future challenges to the ethics of human experimentation. The Milbank quarterly, 73 (4): 489-506

First Ministers of Canada. 2003. First Ministers' Accord on Health Care Renewal. Canada. 
Flannery, Ellen and Sanford N. Greenberg. 1994. Liability exposure for exclusion and inclusion of women as subjects in clinical studies. In Women and health research: Ethical and legal issues of including women in clinical studies, vol. 2, 91-102. Institute of Medicine.

Food and Drugs Act, R.S.C. 1985, C. F-27.

Food and Drug Regulations, C.R.C., c. 870.

Glass, Kathleen Cranley. 2006. Questions and challenges in the governance of research involving humans: A Canadian perspective. In Law and ethics in biomedical research: Regulation, conflict of interest, and liability. Ed. Trudo Lemmens and Duff R. Waring, 35-46. Toronto: University of Toronto Press.

Glass, Kathleen Cranley, and Trudo Lemmens. Research involving humans. 2002. In Canadian health law and policy, 2nd ed., ed. Jocelyn Downie, Timothy Caulfield and Colleen Flood, 459500. Markham: LexisNexis Butterworths.

Hadskis, Michael. 2007. The regulation of human biomedical research in Canada. In Canadian health law and policy, $3^{\text {rd }}$ ed., ed. Jocelyn Downie, Timothy Caulfield and Colleen Flood, 257310. Markham: LexisNexis Butterworths.

Hankivsky, Olena. 2006. Beijing and beyond: Women's health and gender-based analysis in Canada. International journal of health services 36(2): 377-400.

Health Canada. 1999. Women's health strategy. http://www.hc-sc.gc.ca/ahc-asc/pubs/strategwomen-femmes/strateg_e.html. Accessed 31 January 2008.

Health Canada. 2000. Health Canada's gender-based analysis policy. http://www.hc-sc.gc.ca/hlvs/women-femmes/gender-sexe/policy-politique_e.html. Accessed 31 January 2008.

Health Canada. 2004. Good clinical practices. http://www.hc-sc.gc.ca/dhp-mps/compliconform/clini-pract-prat/index_e.html. Accessed 14 January 2008.

Health Canada, 2006a. Blueprint for renewal: Transforming Canada's approach to regulating health products and food. http://www.hc-sc.gc.ca/ahc-asc/branch-dirgen/hpfb-dgpsa/blueprintplan/index_e.html. Accessed 14 January 2008.

Health Canada. 2006b. Using the pharmaceutical safety and efficacy assessment templates (PSEATs) to prepare reports on submissions for marketing authorizations. http://hc-sc.gc.ca/dhpmps/prodpharma/activit/proj/practice-pratique/grp_bpe_procedure_e.html. Accessed 18 June 2007.

Health Canada. 2007. Blueprint for Renewal II: Modernizing Canada's Regulatory System for Health Products and Food. http://www.hc-sc.gc.ca/ahc-asc/branch-dirgen/hpfb-dgpsa/blueprintplan/blueprint-plan_ll_e.html. Accessed 29 January 2008. 
Health Canada, Health Products and Food Branch Inspectorate. 2002. Inspection Strategy for Clinical Trials.

Health Canada, Therapeutic Products Directorate Guidelines. 1997, amended 2006. Inclusion of women in clinical trials. http://www.hc-sc.gc.ca/dhp-mps/prodpharma/applic-demande/guideld/clini/womct_femec_e.html. Accessed 24 January 2008.

Healy, David. 2003. Let them eat Prozac. Toronto: James Lorimer \& Co.

Institute of Medicine. 1994. Women and health research: Ethical and legal issues of including women in clinical studies. Volumes $1 \& 2$.

Institute of Medicine. 2006. The future of drug safety: Promoting and protecting the health of the public. Washington, DC: National Academies of Science.

International Conference on Harmonisation. www.ICH.org. Accessed 24 January 2008.

Kinney E.L., J. Trautmann, J.A. Gold, E.S. Vasell, and R. Zelis. 1981. Underrepresentation of women in new drug trials: Ramifications and remedies. Annals of internal medicine 95: 495-499.

Lalonde, Marc, Minister of National Health and Welfare. 1981. A new perspective on the health of Canadians.

Lemmens, Trudo. 2005. Federal regulation of REB review of clinical trials: A modest but easy step towards an accountable REB review structure in Canada. Health law review 13 (2 \& 3): 3950 .

Lemmens, Trudo and Ron Bouchard. 2007. Regulation of pharmaceuticals in Canada. In Canadian health law and policy, $3^{\text {rd }}$ ed., ed. Jocelyn Downie, Timothy Caulfield and Colleen Flood, 311-365. Markham: LexisNexis Butterworths.

Lemmens, Trudo and Paul B. Miller. 2003. The human subjects trade: Ethical and legal issues surrounding recruitment incentives. Journal of law, medicine \& ethics 31: 398-418.

Lexchin, Joel. 1984 The real pushers: A critical analysis of the Canadian drug industry. Vancouver: New Star Books.

Lippman, Abby. 2006. The inclusion of women in clinical trials: Are we asking the right questions? Women and health protection. http://www.whp-apsf.ca/pdf/clinicalTrialsEN.pdf. Accessed 9 May 2008.

MacIntosh, Constance. 2005. Law, policy and the populations health of Aboriginal Canadians. In Public lealth law and policy in Canada, ed. Tracey M. Bailey, Timothy C. Caulfield, and Nola M. Ries, 327-367. Markham: LexisNexis Butterworths. 
Marcia, Angell. 2004. The truth about the drug companies: How they deceive us and what to do about it. New York: Random House.

McDonald, Michael. 2001. Canadian governance of health research of human subjects: Is anyone minding the store? Health law journal 9: 1-21. http://www.law.ualberta.ca/centres/hli/pdfs/hlj/v9/mcdonaldfrm.pdf. Accessed 9 May 2008.

McDonald, Michael. 2000. The governance of health research involving human subjects. Ottawa: Law Commission of Canada. http://www.ethics.ubc.ca/people/mcdonald/lccmacdonald.pdf . Accessed 1 February 2008.

Medawar, Charles and Andrew Herxheimer. 2003/04. A comparison of adverse drug reaction reports from professionals and users, relating to risk of dependence and suicidal behaviour with Paroxetine. International journal of risk \& safety in medicine 16: 5-19.

Medawar, Charles, Andrew Herxheimer, Andrew Bell, and Shelley Jofre. 2002 . Paroxetine, Panorama and user reporting of ADRs: Consumer intelligence matters in clinical practice and post-marketing drug surveillance. International journal of risk \& safety in medicine 15: 161-69.

Merkatz, Ruth B. 1998. Inclusion of women in clinical trials: A historical overview of scientific, ethical, and legal issues. Journal of obstetric, gynecologic, and neonatal nursing 27(1): 78-84.

Merton, Vanessa. 1993. The exclusion of pregnant, pregnable, and once-pregnable people (aka women) from biomedical research. American journal of law, medicine \& ethics 19(4): 369-451.

Moynihan, R., Iona Heath, and D. Henry. 2002. Selling sickness: The pharmaceutical industry and disease mongering. British medical journal. 324 (7342): 886-91.

Moynihan, Ray and Alan Cassels. 2005. Selling Sickness: How the World's Biggest Pharmaceutical Companies are Turning Us All Into Patients. New York: Nation Books.

Mosca, Lori, Lawrence J. Appel, Emelia J. Benjamin, Kathy Berra, Nisha Chandra-Strobos, Rosalind P. Fabunmi, et al. 2007. Evidence-based guidelines for cardiovascular disease prevention in women: 2007 update. Journal of the American College of Cardiology 49(11):1230-50.

Peppin, Patricia. 2003. Manufacturing uncertainty: adverse effects of drug development for women. International journal of law \& psychiatry 26: 515-32.

Peppin, Patricia and Elaine Carty. 2001. Innovation, myths and equality: Constructing drug knowledge in research and advertising. Sydney law review 23: 543-76.

Rademaker M. 2001. Do women have more adverse drug reactions? American journal of clinical dermatology 2: 349-51. 
Romanow, Roy J. 2002. Building on values: The future of health care in Canada. http://www.healthcoalition.ca/romanow-report.pdf. Accessed 16 May 2008.

Rochon, Paula A., Philip B. Berger, and Michael Gordon. 1998. The evolution of clinical trials: inclusion and representation. Canadian Medical Association journal 159(11): 1373-74.

Rochon, P.A, M A Binns, V. Patel, and J.H. Gurwitz. 1998. Reporting of gender-related information in clinical trials of drug therapy for myocardial infarction. Canadian Medical Association journal 159: 321-327.

Rochon, P.A., P.R. Fortin, K.B. Dear, K.L. Minaker, and T.C. Chalmers. 1993. Reporting of age data in clinical trials of arthritis: Deficiencies and solutions. Archives of internal medicine. 153(2):243-8.

Rosser, Sue V. 1989. Re-visioning clinical research: Gender and the ethics of experimental design. Hypatia 4(2): 125-39.

Ruis Cantero, Maria Teresa, and Maria Angeles Pardo. 2006. European medicines agency policies for clinical trials leave women unprotected. Journal of epidemiology and community health 60: 911-13.

S.O.R./2001-203 [Clinical Trial Regulations]. 2001. Regulatory impact analysis statement. Canada Gazette 135(13).

Tri-Council policy statement: Ethical conduct for research involving humans. 1998, amended 2000, 2002, and 2005. http://pre.ethics.gc.ca/english/policystatement/policystatement.cfm. Accessed 2 February 2008.

Tudiver, Sari. 2006. Health Canada, Discussion report \#21. Gender based analysis in drug regulation. http://hc-sc.gc.ca/dhp-mps/homologationlicensing/develop/proglic_homprog_discus_e.html. Accessed January 15, 2008.

United Nations, Fourth World Conference on Women in Beijing. 1995. Platform for action.

United States FDA. 1993. Guideline for the study and evaluation of gender differences in the clinical evaluation of drugs. Federal register 58: 39406-16.

United States General Accounting Office. 1990. National Institutes of Health: Problems in implementing policy on women in study populations. GAO/T-HRD-90-38.

United States General Accounting Office. 2001a. Drug safety: Most drugs withdrawn in recent years had greater health risks for women. http://www.gao.gov/new.items/d01286r.pdf. Accessed 9 May 2008. 
United States General Accounting Office. 2001b. Women's health: Women sufficiently represented in new drug testing, but FDA oversight needs improvement. GAO-01-754.

United States General Accounting Office. 2006. Drug safety: Improvement needed in FDA's postmarket decision-making and oversight process. Report No. GAO-06-402. http://www.gao.gov/new.items/d06402.pdf. Accessed 10 February 2007.

Waxman, Representative Henry A. 2005. Memorandum to the United States House of Representatives Committee on government reform: The marketing of Vioxx to physicians. Washington, D.C.: Congress of the United States.

Wilson, K. 1984. Sex-related differences in drug disposition in man. Clin. Pharmacokinet. 9: 189-202.

Writing Group for the Women's Health Initiative Investigators. 2002. Risks and benefits of estrogen plus progestin in healthy postmenopausal women: principal results from the Women's Health Initiative randomized controlled trial. Journal of the American Medical Association 288: 321-33.

Women's Health Initiative. http://www.nhlbi.nih.gov/whi. Accessed 27 January 2008.

Women and Health Protection. 2006. Submission to Health Canada in response to Blueprint for Renewal. http://www.whp-apsf.ca/en/documents/blueprint.html. Accessed 12 March 2007. 